\title{
Resenha
}

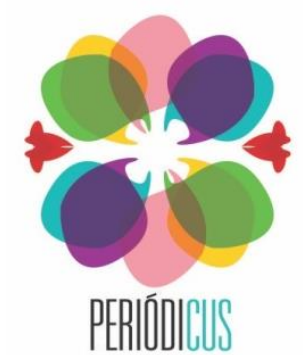

ISSN: 2358-7844

п. 12, v. 1 nov.2019-abr.2020 р. $502-505$

\section{Vivências da sexualidade homoafetiva em Cabo Verde}

\author{
Ricardo Pagliuso Regatieri ${ }^{1}$
}

\begin{abstract}
Livro resenhado: SILVA, Lurena Delgado. Homossexuais, gays e travestis em Mindelo:
\end{abstract} entre identidades e resistências. Praia: Livraria Pedro Cardoso, 2018.

Homossexuais, gays e travestis em Mindelo: entre identidades e resistências é o resultado do Mestrado em Ciências Sociais da pesquisadora cabo-verdiana Lurena Delgado Silva. Trata-se de uma radiografia de vivências da sexualidade homoafetiva no exato momento em que esta começava a ganhar visibilidade no país africano em virtude da organização das duas primeiras Paradas do Orgulho Gay em Cabo Verde em 2013 e 2014. O arquipélago de Cabo Verde se situa a quase $600 \mathrm{~km}$ da costa ocidental da África e tinha uma população total estimada em cerca de 560 mil habitantes em 2017. A maior cidade do país é a capital, Praia, mas a segunda maior cidade, Mindelo, é considerada sua capital cultural. Mindelo, onde Silva realizou sua pesquisa, é a terra natal daquela que provavelmente é a cabo-verdiana mais conhecida internacionalmente, a cantora Cesária Évora, que dá nome ao aeroporto local. A cidade é também conhecida por seu Carnaval. A pesquisa de campo da autora ocorreu entre 2012 e 2014 e foi realizada por meio de 22 entrevistas com homens que se autodefinem como gays, com idades entre 17 e 41 anos, facilitadas pela mediação da Associação Gay Cabo-Verdiana Contra a Discriminação (AGCCD), fundada em 2011 em Mindelo.

O trabalho de Silva se divide em quatro capítulos, antecedidos por uma introdução e seguidos por algumas considerações finais. Na introdução, além de brevemente apresentar informações sobre Cabo Verde, Mindelo e a AGCCD, a autora, que se autodefine como uma mulher heterossexual, escreve que o tema de sua pesquisa derivou de seu contato com o ativismo gay, os debates sobre relações de gênero e, de modo mais geral, do cenário mais amplo de democratização do país desde a década de 1990. Segundo a autora, os estudos sobre gênero e

\footnotetext{
${ }^{1}$ Professor do Departamento de Sociologia e do Programa de Pós-Graduação em Ciências Sociais da Universidade Federal da Bahia (UFBA). Possui Graduação em Ciências Sociais, Mestrado em Sociologia e Doutorado em Sociologia pela Universidade de São Paulo (USP). Realizou período de Doutorado sanduíche na Johann Wolfgang GoetheUniversität Frankfurt. Foi pesquisador visitante e Research Professor na Korea University em Seul. Foi docente na Graduate School of International Studies da Korea University e na Graduate School da Hankuk University of Foreign
} Studies de Seul. E-mail: ricardo.pagliuso@ufba.br 
sexualidade em Cabo Verde apresentam um viés heteronormativo, ou seja, “essas discussões têm sido baseadas na ideia de que o natural é uma relação entre um homem e uma mulher, excluindo qualquer possibilidade de uma relação entre duas pessoas do mesmo sexo" (p. 17). Silva afirma que o objetivo geral de seu trabalho é "analisar, do ponto de vista socioantropológico, as dinâmicas de construção identitária, compreender como se vivencia a homossexualidade no contexto de São Vicente [ilha na qual se situa a cidade de Mindelo] e o significado da associação para seus integrantes" (p. 22). Na parte final da introdução, são delineados os temas tratados por cada capítulo.

O primeiro capítulo se estrutura em torno de considerações metodológicas sobre o trabalho de campo levado a cabo pela autora. Segundo a autora, a constituição do ativismo gay em Mindelo data da década de 1990, com a realização do primeiro concurso de Miss Gay e a criação do grupo de Carnaval Pomba Gira, ambas em 1998. Foi dessa movimentação que nasceu, pouco mais de uma década depois, a AGCCD. Silva, que não conhecia os membros dessa associação, entrou em contato com eles e foi bem recebida como pesquisadora interessada em estudar o grupo no âmbito de seu Mestrado. Ela explica que sua pesquisa foi orientada por uma metodologia qualitativa com forte base etnográfica, utilizando-se das seguintes técnicas: “(1) conversas informais e entrevistas semiestruturadas, (2) notícias veiculadas na imprensa cabo-verdiana, e (3) uma combinação de várias técnicas recorrentes em antropologia para o registro etnográfico: observação participante nos locais onde vivem, dos desfiles de carnaval, festas, casas de amigos onde costumam frequentar, seguida do registro no caderno de campo para reconstituir trajetórias e traçar o perfil dos participantes” (p. 29). Silva diz que mais da metade dos entrevistados morava em Fonte Filipe, uma área pobre da periferia de Mindelo que a autora chama de "zona gay", sobre a qual os próprios gays que lá vivem fazem brincadeiras, "dizendo que [nessa área] existe uma pedra quente e todas as pessoas que nela sentarem se tornam gays, que nas ruas de São Filipe não se pode fazer xixi, porque se torna gay, colocar o pênis para fora em plena rua torna-se gay" (p. 33).

O segundo capítulo começa com uma revisão bibliográfica sobre identidade de gênero e sexualidade e a autora afirma que procurará pensar o caso de Mindelo à luz dessa bibliografia, que inclui Butler, Scott, Haraway e Strathern. No entanto, a partir de sua segunda parte, intitulada "Identidades de gênero em campo", fica claro que Silva mobiliza muito mais definições e percepções de gênero e sexualidade que encontrou em sua pesquisa de campo, além de recorrer a outras pesquisas empíricas similares à sua. Como já apontado, todos os 
interlocutores de Silva se autodefinem como gays, ou seja, como "homens que gostam de homens" (p. 54). Dentre eles, uma parte se trasveste e, segundo a autora, as travestis "levam uma vida completamente feminina, desde o nome feminino adotado à forma de se vestir e de se comportar", identificando-se "como sendo do gênero feminino" (p. 55). A terceira parte do capítulo trata dos relacionamentos homoafetivos em Mindelo. Em Cabo Verde, assim como nos demais países africanos de língua oficial portuguesa (Palop) e em alguns outros países do continente, relações sexuais com pessoas do mesmo sexo não são criminalizadas, ainda que só na África do Sul a união civil e o casamento sejam reconhecidos. A despeito de as relações homoafetivas não serem proibidas no arquipélago, apenas dois dos entrevistados por Silva se encontravam em relações conjugais, sendo que os demais eram solteiros e se relacionavam com homens "heterossexuais", que faziam o papel de "ativos" na relação sexual, e não com outros autodefinidos como gays. Como os "heterossexuais" não assumem essas relações, que são em geral fugazes, é difícil manter algum tipo de ligação afetiva duradoura. Apesar desses papeis sexuais rígidos, Silva afirma, baseada em seus interlocutores, que existe uma certa fluidez sexual em Mindelo, no sentido de que é muito comum que "heterossexuais" pratiquem sexo com gays. As duas partes finais do capítulo tratam da prostituição, nas figuras da prostituição gay com clientes locais ou estrangeiros e a dos jovens "heterossexuais" com clientes gays e geralmente mais velhos.

No terceiro capítulo, a autora aborda trajetórias dos interlocutores no que diz respeito à família, à escola, ao trabalho e às relações sociais mindelenses de forma mais ampla. Na família, Silva constata que, de modo geral, existe oposição e rejeição, que em alguns casos se converte em algum tipo de aceitação. O percurso na escola aparece como conturbado, e a autora conclui que "a escola se revela um lugar que não se encontra preparado para a diferença", constituindo um "ambiente hostil" que acaba por expulsar aqueles que não se enquadram nas normas de gênero hegemônicas (p. 90). A despeito das dificuldades apontadas, Silva, baseada nas percepções dos interlocutores, escreve que, em vista do contexto cabo-verdiano, as pessoas na ilha de São Vicente "têm uma mentalidade mais aberta" e a "religião católica não tem uma influência tão acentuada como noutras ilhas" (p. 93). Desde que "fique tudo encoberto", que as pessoas "não desestabilizem as normas sociais" e saibam se "comportar" consoante essas normas, em Mindelo é possível viver a sexualidade homoafetiva de forma mais tranquila do que em outros lugares do arquipélago (p. 93).

O quarto e último capítulo trata propriamente da AGCCD enquanto veículo de promoção da identidade gay e de luta por direitos. No que tange ao primeiro ponto, Silva destaca a 
organização das Paradas do Orgulho Gay em Mindelo, que propiciam visibilidade ao grupo. No que diz respeito ao segundo, a associação visa a inclusão na legislação cabo-verdiana de "direitos civis como o casamento, união de fato, direito à herança e seguridade social", além da criação de políticas de saúde, formação profissional e emprego para a população LGTB (p. 98). Outra reivindicação é a inclusão do debate sobre diversidade sexual no currículo escolar. Nas considerações finais, a autora retoma, de forma resumida, questões apresentadas ao longo do livro e finaliza o trabalho dizendo que ele tem como intuito contribuir para a melhoria das condições de vida dos homossexuais em Cabo Verde.

O livro de Lurena Delgado Silva é seguramente uma peça importante no recente debate sobre diversidade sexual nas esferas acadêmica e pública de Cabo Verde. Chamou atenção deste resenhista o fato de Homossexuais, gays e travestis em Mindelo poder ser encontrado à venda não só em livrarias, mas também em cafés e lojas, as mais diversas do principal centro urbano da ilha de São Vicente. Seu ponto forte é o registro etnográfico de uma população cujas vozes começam agora, pouco a pouco, a ser ouvidas. Em termos de análise, o trabalho não inova, e fica aquém de referências teóricas reivindicadas pela autora. Transparece ao longo do livro, por exemplo, um certo viés conservador no que diz respeito à reafirmação das noções de "masculino" e "feminino". A despeito disso, Homossexuais, gays e travestis em Mindelo permite acessar vivências homoafetivas no arquipélago do outro lado do Atlântico e é valioso para todos os que se interessam pelo tema de modo geral ou de forma especial por sua situação na África ou nos Palop. 